\title{
Destinos turísticos y capital creativo: el caso de la costa del sol en el sur de España
}

\section{Tourist destinations and creative capital: the case of costa del sol in southern Spain}

\author{
Yolanda Romero-Padilla ${ }^{1} \mathbb{C}$, Enrique Navarro-Jurado ${ }^{2}$ (c) \\ y José-María Romero-Martínez ${ }^{3}$
}

\begin{abstract}
RESUMEN
Determinados destinos turísticos han incrementado su conectividad convirtiéndose en lugares más dinámicos acordes con las tendencias del mundo contemporáneo, donde se desenvuelve en su hábitat la clase creativa. La investigación analiza la relación entre desarrollo turístico y capital creativo en la Costa del Sol en el Sur de España. Los resultados cuantitativos muestran una dinámica conocida en otras zonas turísticas del Mediterráneo: el índice de creatividad se localiza en zonas compuestas por aglomeraciones urbanas importantes y destinos turísticos, donde se combinan Tolerancia, Tecnología y Talento. Esta es la base de la calidad de ubicación (Territorio) donde el estudio cualitativo muestra una mayor percepción de equilibrio entre el desarrollo de la vida profesional orientada al mercado global y el estilo de vida hedonista, orientado al disfrute de la calidad de vida y el placer. Los resultados confirman cómo los destinos empiezan a trascender las actividades turísticas, convirtiéndose en territorios más complejos.
\end{abstract}

Palabras clave: Capital creativo, evolución de destinos turísticos, migraciones por estilos de vida, Costa del Sol, destinos litorales.

\begin{abstract}
Certain tourist destinations have increased their connectivity, becoming more dynamic places in accordance with the trends of the contemporary world, where the creative class develops in its habitat. The research analyses the relationship between tourism development and creative capital on Costa del Sol a mass tourist destination in southern Spain. The quantitative results found a dynamic known in other tourist areas of the Mediterranean: the creativity index is located in areas made up of major urban agglomerations and tourist destinations, where Tolerance, Technology and Talent are combined. This is the basis of the quality of location (Territory) where the qualitative study shows a greater perception of balance between the development of professional life oriented to the global market and the hedonistic lifestyle, oriented to enjoyment of quality of life and pleasure. The results confirm how destinations are transferred to tourist activities, becoming more complex territories.
\end{abstract}

Keywords: Creative capital, evolution of tourist destinations, lifestyle migrations, Costa del Sol, coastal destinations.

Departamento de Organización de empresas y marketing, Facultad de Comercio y Turismo, Universidad Complutense de Madrid, España. Correo electrónico: yromerop@ucm.es

Departamento de Geografía. Facultad de Turismo, Instituto universitario de investigación, inteligencia e innovación turística, Universidad de Málaga, España. Correo electrónico: enavarro@uma.es

Departamento de Expresión gráfica, arquitectónica y en la ingeniería, E.T.S. Arquitectura, Universidad de Granada, España. Correo electrónico: jmr2@ugr.es 
La Geografía no muere con la globalización, sino que evoluciona (Harvey, 2004; Murray y Blázquez, 2009). El funcionamiento económico-financiero es la base que explica los procesos geográficos. Se transforman los límites espaciales y temporales conformando redes globales, sin embargo, la localización sigue siendo fundamental dentro de estas redes (Borja y Castells, 1997; Sassen, 2004; Sennett, 2004; Harvey, 2013). Los lugares, se convierten en nodos del entramado de relaciones y actuaciones globales y locales, y su relevancia queda definida principalmente por tres aspectos: (1) la naturaleza de las relaciones; (2) la diversidad y cantidad de relaciones; y (3) los territorios con los que se relacionan. Los nodos más importantes se identifican con las ciudades globales (Sassen, 2004; Hall, 2004), que son grandes aglomeraciones urbanas y los centros financieros y comerciales del mundo.

Las ciudades globales son sumideros y emisores de información, conocimiento, creatividad e innovación (Sassen, 2004; Borja y Castells, 1997; Hall, 2004; Florida, 2004). El grado de movilidad de buena parte de la población que la habita es elevado; de manera interna, y hacia las zonas con las que se encuentran conectadas. Son los lazos con sus tradicionales periferias de abastecimiento de recursos, mano de obra o placer. Dentro de esta red de funcionamiento global, determinados nodos cuentan con una variedad y densidad de flujos de personas, información, conocimiento, ideas y capitales muy elevadas, y su tejido social tiende a una mayor diversidad, apertura y tolerancia hacia colectivos y estilos de vida diferentes (Florida, 2004; Borja y Castells, 1997; Castells, 2015). Según la tesis de Florida (2004), los lugares que concentran a la vez Tolerancia, Tecnología y Talento (3Ts) son las ubicaciones preferentes para la localización de la clase creativa, a la que considera motor del crecimiento económico (Florida, 2004).

En el plano turístico, determinados destinos juegan un papel importante como nodos de ocio en la red global de funcionamiento (Romero-Padilla, Navarro-Jurado, Malvárez, 2016) porque la evolución de dichos destinos ha supuesto una transformación profunda, pasando a ser territorios contemporáneos, cosmopolitas. Son lugares con características globales (interculturalidad, hipermovilidad, conectividad externa elevada, fuerte dinamismo demográfico...), que desarrollan un socio-ecosistema abierto propio del ciudadano urbanita contemporáneo. Estos destinos se relacionan con los principales núcleos generadores y emisores del movimiento de población, ideas y capital financiero. Estudios recientes ayudan a entender el capital relacional de los destinos turísticos en el mundo en red, poniendo la atención en las relaciones territoriales (Agarwal, 2005, 2012), las redes sociales globales (Larsen, Urry, Axhausen, 2007) o los migrantes por estilos de vida (Benson y O'Reilly, 2009).

Esta investigación tiene como objetivo ahondar en la relación entre el desarrollo turístico y el capital creativo en la evolución de los destinos turísticos. Para ello se parte de una revisión de las principales teorías de evolución de los destinos turísticos y del análisis de otras teorías de interés para explicar los cambios relacionados con un mayor dinamismo del destino, como son las migraciones por estilos de vida (Benson y O’Reilly, 2009) y la clase creativa (Florida, 2004, 2010). La segunda parte del trabajo muestra la aplicación del Índice Global de Creatividad (enfoque cuantitativo) y la Calidad de la Ubicación (enfoque cualitativo) tomando como caso de estudio la Costa del Sol, uno de los destinos turísticos más importante del Mediterráneo. Finalmente se extraen las conclusiones y se proponen nuevas vías de investigación. 


\section{Enfoques teóricos de la evolución de destinos turísticos: limitaciones para su aplicación en destinos litorales dinámicos}

Tradicionalmente la literatura ha analizado la evolución del desarrollo turístico con la teoría del ciclo de vida de los destinos turísticos (CVDT) enunciado por Butler en 1980 (Butler 2011), siendo la aportación que mayor repercusión en este campo ha tenido desde el punto de vista académico y político. Según esta teoría los destinos parecen determinados en la última fase de su desarrollo al declive, el estancamiento o la renovación con diferentes grados intermedios. Las limitaciones conceptuales, metodológicas y prácticas propias de la simplicidad del modelo han contribuido tanto a su éxito como a su crítica desde los años ochenta (Butler 2011; Vera y Baños, 2010). Sin embargo, este modelo tiene tres limitaciones que influyen en la investigación presente.

Primero, no sirve para explicar la complejidad urbana y la vitalidad de la función turística que algunos destinos siguen manteniendo a pesar de estar en una fase de supuesta madurez-estancamiento en los destinos. Incluso la fase de declive contempla el incremento de las transacciones inmobiliarias como indicio de decadencia ligando este hecho a la transformación del alojamiento de oferta reglada en oferta residencial (Agarwal, 2002), y siendo el siguiente paso el aumento de la función urbana y abandono de la actividad turística (Antón Clavé, 2011). Obviamente, este modelo no contempla el desarrollismo inmobiliario-turístico propio de ciclos especulativos (Navarro-Jurado, Thiel-Ellul y Romero-Padilla 2015) ni contempla el aumento de la función urbana como un incremento de la complejidad y diversidad del destino. Segundo, el éxito de la evolución del destino y de las estrategias de rejuvenecimiento se basan en el incremento sostenido en el tiempo del número de turistas, dejando al margen la rentabilidad del tipo de visitantes, con relación al gasto por turista y también en el coste-rentabilidad de las inversiones públicas y privadas realizadas en las estrategias de crecimiento-mantenimiento-rejuvenecimiento del CVDT. Tercero, un modelo basado en el crecimiento ilimitado del número de turistas no tiene cabida en las estrategias de desarrollo sostenible de un destino, puesto que la sostenibilidad implica reconocer y establecer límites (Saarinen, 2006).

Otra teoría que tiene en cuenta los cambios de la producción fordista a la posfordista y que ha emergido con fuerza es la de reestructuración de destinos turísticos (Agarwal, 2002). La teoría de la restructuración encaja mejor con algunos destinos litorales internacionales consolidados que han evolucionado hacia estructuras territoriales complejas; sin embargo, sigue siendo de corte fundamentalmente sectorial. Agarwal relaciona la teoría del CVDT de Butler, con la reestructuración económica y productiva experimentada en sectores industriales y de servicios públicos, que explica la repercusión de los factores externos en la evolución del destino. Según este enfoque el declive puede definirse como resultado del complejo entramado de fuerzas internas y externas que interactúan en el destino, sin estar necesariamente vinculado a alguna fase concreta del ciclo interno o de la economía, y siendo la reconversión un proceso constante destinado a alcanzar un mayor grado de singularidad.

Existen teorías más complejas e interesantes para su aplicación en la evolución de los destinos litorales. Por ejemplo, el modelo de Gormsen (1997) explica la evolución y transformación espacial del turismo litoral a escala global, produciendo periferias del placer. La expansión de las zonas tu- 
rísticas se explica en esta teoría a partir de los cambios en las formas de producción y los sistemas de comunicación y transporte, mostrando las conexiones entre los destinos y los países productores emisores de clase ociosa. De esta manera, es posible relacionar las revoluciones industriales y los ciclos de Kondratieff con la expansión de las periferias del placer (Rullán, 2008). Gormsen (1997) plantea una primera periferia en los primeros enclaves turísticos (Canal de la Mancha, Mar del Norte, costa atlántica de EE.UU., etc.) asociados a la revolución industrial focalizada en Gran Bretaña y sus potencias coloniales; y se extiende hasta llegar a una cuarta periferia del placer con la tercera revolución (hipermovilidad, comunicación inmediata, capitalismo global organizado en red...) donde el turismo se desarrolla a escala global.

Otros autores (Navarro et al., 2015) proponen un enfoque que une los modelos de Butler y Gormsen para analizar, en un contexto de capitalismo mundializado, la expansión del turismo a escala global en destinos litorales. Se observa una repetición del modelo de ciclo de vida para cada una de las periferias. En una lógica capitalista de acumulación flexible, el capital al disminuir la perspectiva de crecimiento de los rendimientos salta de una periferia en su ciclo de estancamiento, y comienza la fase de exploración en la siguiente periferia, y así sucesivamente. Los nuevos destinos de la cuarta periferia se crean en un mundo de funcionamiento global en red, con una economía cada vez más acelerada, inestable y volátil. En consecuencia, las fases que componen el CVDT se van acortando en cada periferia, "a mayor velocidad en las fases de desarrollo menor es la duración del ciclo" (Butler, 2011:13), lo que repercute en los "nuevos" destinos turísticos de la cuarta periferia de manera preocupante puesto que muchos de ellos emergen en países en vías de desarrollo. Además, el desarrollo inmobiliario, propio de fases más avanzadas en el ciclo de vida (Agarwal, 2002; Antón Clavé, 2011), empieza a aparecer en las fases tempranas del desarrollo del destino; en algunos casos, la oferta hotelera es meramente testimonial o inexistente ante el avance monocultivo de la oferta inmobiliaria de segunda residencia. El enfoque de Navarro et al. (2015) permite comprender el desarrollo turístico desigual y, por tanto, el por qué no todos los destinos evolucionan hacia una mayor complejidad urbana.

Estos modelos y enfoques ayudan a entender la complejidad que algunos destinos litorales internacionales han adquirido y sus múltiples relaciones con las ciudades globales, pasando a formar parte del mismo sistema de funcionamiento. En este contexto, los ejemplos de territorios dinámicos de algunos destinos en el mediterráneo español contrastan con el proceso de decadencia que anunciaban distintas investigaciones (Morgan, 1991; Knowles y Curtis 1999; Poon 1993) basándose en el determinismo de los modelos evolutivos. Es necesario ahondar en los elementos que caracterizan las nuevas etapas de evolución en estos destinos turísticos que empiezan a dejar de ser meras periferias globales.

\section{El capital creativo en las nuevas etapas de la evolución de destinos turísticos}

\section{Relaciones locales y globales de los destinos turísticos}

En indiscutible que las relaciones globales y locales de los destinos turísticos es cada vez más importante. Estudios como el de Agarwal (2012) muestran la importancia de integrar el enfoque de relaciones territoriales en la planificación de un destino, de manera general, y especialmente 
en destinos litorales en proceso de reestructuración. La autora explica la relación global-local de los destinos turísticos como nodos (locales) de una red (global), donde las ventajas competitivas vienen determinadas por la capacidad del destino de posicionarse dentro de la red global en términos de acceso, conectividad y capacidad de intercambiar información y conocimiento en la red. Este enfoque también ayuda a comprender el desarrollo desigual turístico, ya que el dinamismo económico, social y cultural de algunos destinos no se entiende sin la composición de sus relaciones globales económicas, sociales y culturales. Larsen, Urry, Axhausen (2007) estudian los efectos que los movimientos migratorios de cualquier índole generan a medio y largo plazo en los movimientos turísticos. Las personas que se desplazan de su lugar de origen generan relaciones recíprocas entre el lugar de origen y el(los) nuevo(s) lugar(es) de residencia, induciendo desplazamientos turísticos asociados a visitas de familiares y amigos.

Para esta investigación son especialmente interesantes los estudios que centran la atención, dentro de los movimientos migratorios, en los migrantes que se mueven por motivaciones asociadas a su estilo de vida. Según Benson y O'Reilly (2009) la migración por estilos de vida es una consecuencia más de las múltiples elecciones que la sociedad posmoderna o líquida -en términos de Bauman (2013)- obliga a tomar durante su trayectoria vital. Las decisiones se ven condicionadas por su habitus -en términos de Bourdieu (1986) se refiere a las estructuras de pensamientos, percepciones, expresiones y acciones asociados a la posición social que ocupa la persona- y su nivel de capital simbólico. Por tanto, el capital simbólico (que incluye el capital educacional, cultural y social) tiene un impacto directo en la decisión de migración, en la elección del destino y en la vida que mantendrá en el destino. Los autores (Benson y O'Reilly, 2009) sugieren tres tipologías de migraciones por estilos de vida basadas en la elección del destino: (1) Turistas residenciales. Representan la búsqueda del hedonismo, hacen del turismo una forma de vida y principalmente se localizan en destinos litorales de sol y playa. En el contexto europeo, buscan el estilo de vida mediterráneo en aspectos diversos (gastronomía, un ritmo de vida más lento y la 'vida en la calle') y destacan lugares como el Algarve, Malta, la Costa Blanca, siendo España un destino favorito. (2) Buscadores de los ideales rurales. Persiguen un sentimiento de vuelta a la tierra, a una vida sencilla y el espíritu de comunidad. Se pueden encontrar ejemplos de este tipo de migraciones en zonas del interior de Francia, España o Rumania en el contexto europeo, o Panamá y Costa Rica en el estadounidense. (3) Burgueses bohemios. Buscan un estilo de vida basada en los ideales bohemios. Se centran en lugares que ofrezcan una cierta experiencia espiritual, artística, cultural o creativa. Los destinos que atraen a este tipo de migrantes son diversos, con ejemplos en Florencia (Italia), Mikonos (Grecia) o Deià (Mallorca, España).

Estos burgueses bohemios forman parte de un grupo privilegiado no sólo desde el punto de vista económico sino del acceso a posibilidades de decisión de estilos de vida particulares y propios del mundo desarrollado y, especialmente de las ciudades globales. Entre las características asociadas a los estilos de vida que buscan este tipo de migrantes se pueden incluir "la buena vida, el escape de historias pasadas individuales o de la comunidad, y las oportunidades para la autorrealización, las estrategias tras la migración muchas veces también incluyen la renegociación del equilibrio de la vida laboral, el mantenimiento de la calidad de vida y la liberación de las limitaciones anteriores"4 (Benson y O'Reilly, 2009: 610). Muchas de estas migraciones han tenido

Traducción del original: "the good life, escape from past individual and community histories, and the opportunity for self-realisation, strategies post migration often include the re-negotiation of the work-life balance, maintaining quality of life and freedom from prior constraints". 
en los viajes una manera de 'catar' formas de vida diferentes durante sus estancias, algo que tiene una tendencia creciente en un contexto de aumento de los viajes internacionales y en el que progresivamente se mezclan y diluyen los espacios de ocio y trabajo (Urry y Lash, 2005; Larsen, Urry, Axhausen, 2007). Otro aspecto a tener en cuenta en las migraciones por estilo de vida es la puesta en marcha por parte de estos migrantes de pequeñas empresas y actividades de autoempleo, como medio de poder obtener ingresos para mantener sus aspiraciones de estilos de vida más que con el fin de hacer negocio (Stone y Stubbs, 2007); es lo que empieza a denominarse clase creativa.

\section{La clase creativa y la calidad de ubicación}

Asumiendo la creatividad como elemento fundamental de la sociedad y del desarrollo económico global, Florida (2004) con la teoría de la "clase creativa" pone el foco de atención en el factor humano. Bajo esta etiqueta agrupa a las personas que generan valor económico a partir de la aplicación intensiva de su conocimiento y capacidad creativa (profesionales que resuelven problemas complejos y/o generan nuevas ideas, tecnologías o contenidos). Las ciudades creativas se encuentran a la vanguardia de los cambios producidos por las tendencias de la globalización contemporánea, ligando su evolución a ésta (Scott, 2006; Florida, 2004; Landry y Bianchini, 1995; UNCTAD, 2010).

A partir de la configuración del Índice Global de Creatividad, Florida (2004) realizó diferentes aplicaciones y estudios cuantitativos para analizar la concentración de clase creativa en determinados lugares. En sus aplicaciones iniciales el índice global se compuso por diferentes indicadores agrupados en los subíndices de tolerancia (población extranjera, presencia de homosexuales, población ocupada en el ámbito artístico), tecnología (actividades de alta tecnología e innovación medida en patentes) y talento (población con estudios universitarios). Posteriormente se han ido ampliando estos indicadores conforme se adaptaba el índice de creatividad a las realidades de cada zona de estudio.

Para determinar la capacidad de atracción de capital creativo de un lugar, Florida (2010) pone el foco en seis características cualitativas de la calidad de ubicación: (1) Mercados laborales densos. (2) Estilo de vida, compaginando el trabajo con el disfrute del ocio. (3) Interacción social, con relaciones más abundantes, pero también más superficiales, frágiles e inestables en la sociedad líquida (Bauman, 2013; Sennett, 2004). (4) Diversidad, con una sociedad de mentalidad tolerante, con diferentes orientaciones sexuales y edades, con mezcla de influencias y cosmopolitismo, una sociedad donde la gente de fuera se siente acogida, y abierta a nuevas ideas y formas de vida (Sassen, 2004; Castells, 2015). (5) Autenticidad, interpretada como oposición a lo genérico, como convivencia de lo nuevo y lo viejo, que atiende a la singularidad de un lugar y rechaza la tematización y el espacio basura (Koolhaas, 2004; 2008). (6) Identidad. En la actual sociedad líquida las instituciones que contribuian de manera fundamental al desarrollo de la identidad y subjetividad de los individuos están perdiendo su significado y estabilidad (Sennett, 2004, Bauman, 2013). Por esta razón la ubicación residencial y la implicación en la comunidad están pasando a ser fuente de construcción de identidad.

En definitiva, la calidad de la ubicación incluye tres dimensiones (Florida, 2004: 309): qué hay (entorno físico), quién hay (personas) y qué pasa (vitalidad de la vida en la calle, actividades...). 
Los lugares que logran el éxito no ofrecen una única cosa, sino que proporcionan un amplio abanico de opciones de calidad de ubicación, para distintas personas en distintos momentos de sus vidas." (Florida, 2010: 311).

La teoría de la clase creativa ha sido estudiada por numerosos investigadores y también ha recibido críticas por sus características conceptuales, su planteamiento metodológico y sus implicaciones políticas (Malanga, 2004; Berry, 2005; Andersen et. al. 2010; Perry, 2011). El propio autor ha revisado de manera reciente esta teoría, entre otras cosas, por la relación existente entre el índice de creatividad y el índice de desigualdad (Florida, 2017). Sin embargo, esta teoría ha sido escasamente estudiada en contextos turísticos, destacando algunos estudios centrados en destinos urbanos (Richards, 2014), en el litoral Mediterráneo español y las Islas Canarias (González-Reverté et al., 2016) y en el contexto de Cataluña (Olano-Pozo, 2019). Esta investigación sigue esta línea, aplicando el índice de creatividad y avanzando mediante la profundización desde una perspectiva cualitativa en las motivaciones de la clase creativa que elige un destino turístico para vivir.

\section{Caso de estudio y metodología}

Atendiendo al marco teórico expuesto, se aplica el Índice de Creatividad (análisis cuantitativo) y el concepto de calidad de ubicación (estudio cualitativo) al litoral de la provincia de Málaga con la Costa del Sol como caso ejemplarizante de destino litoral internacional consolidado dentro del litoral Mediterráneo español (Figura No1).

La provincia de Málaga tiene una población aproximada de 1'6 millones, distribuidos en 86 municipios de interior y sólo 15 municipios litorales, pero en la actualidad la dinámica socioeconómica y urbana del litoral es la que concentra la mayor parte de la población y de la actividad económica, si bien se extiende al interior con mayor o menor intensidad: los límites de la Costa del Sol son difusos. Esto se observa por ejemplo en la densidad de población, con una media provincial en 2017 de 223 hab./ $\mathrm{km}^{2}$ muy por encima en comparación con otras provincias de Andalucía: Cádiz (167 hab./ km²), Sevilla (138 hab./km²), Almería (81 hab./km²), Granada (72 hab./ $\left.\mathrm{km}^{2}\right)$, Córdoba $\left(57 \mathrm{hab} . / \mathrm{km}^{2}\right)$, Huelva $\left(51 \mathrm{hab} . / \mathrm{km}^{2}\right)$, Jaén (48 hab. $\left./ \mathrm{km}^{2}\right)$. que presentan datos muy inferiores y presentando los municipios litorales con mayor tradición turística valores ampliamente mayores como es el caso de Fuengirola (7.205 hab. $\left./ \mathrm{km}^{2}\right)$, Torremolinos (3.402 hab./km²), Benalmádena (2.560 hab./ $\mathrm{km}^{2}$ ) o Marbella (1.209 hab./ $\left.\mathrm{km}^{2}\right)$. El turismo es la actividad principal (18\% del empleo en 2014 y 16\% del tejido productivo en 2015). La Costa del Sol está conectada a las principales ciudades de Europa a través del aeropuerto más importante del sur de España (19 millones de pasajeros en 2018) y el cuarto de España. La provincia recibe 9'6 millones de turistas en 2018 (en torno al 32\% del total de Andalucía), y cuenta con más de 255.000 plazas de alojamiento. Forma parte de los lugares habituales de ocio, recreación, vida y trabajo de los colectivos con mayor movilidad internacional de Europa, procedentes especialmente de ciudades como Londres, Barcelona, Madrid, Mánchester, Liverpool... desde donde parten los mayores flujos de pasajeros hacia Málaga (Turismo y Planificación Costa del Sol, 2014).

Pero Costa del Sol, no se entiende sin su contexto Mediterráneo. Esta región es punto de nacimiento de la civilización occidental y encrucijada de los continentes africano, asiático y europeo, con un mar y clima comunes que en la actualidad son condicionantes y motores de atracción de 
las migraciones por estilos de vida y el desarrollo urbano-turístico masivo del litoral. Se fundamenta en la mezcla y variedad, tanto del paisaje físico como humano, en palabras de Braudel el Mediterráneo es una encrucijada viejísima. (1987: 9-11).

A lo largo del estudio nos referiremos a la zona de análisis como Málaga-Costa del Sol para hacer referencia a todo el litoral malagueño.

Figura N¹

Mapa de localización de la zona de estudio

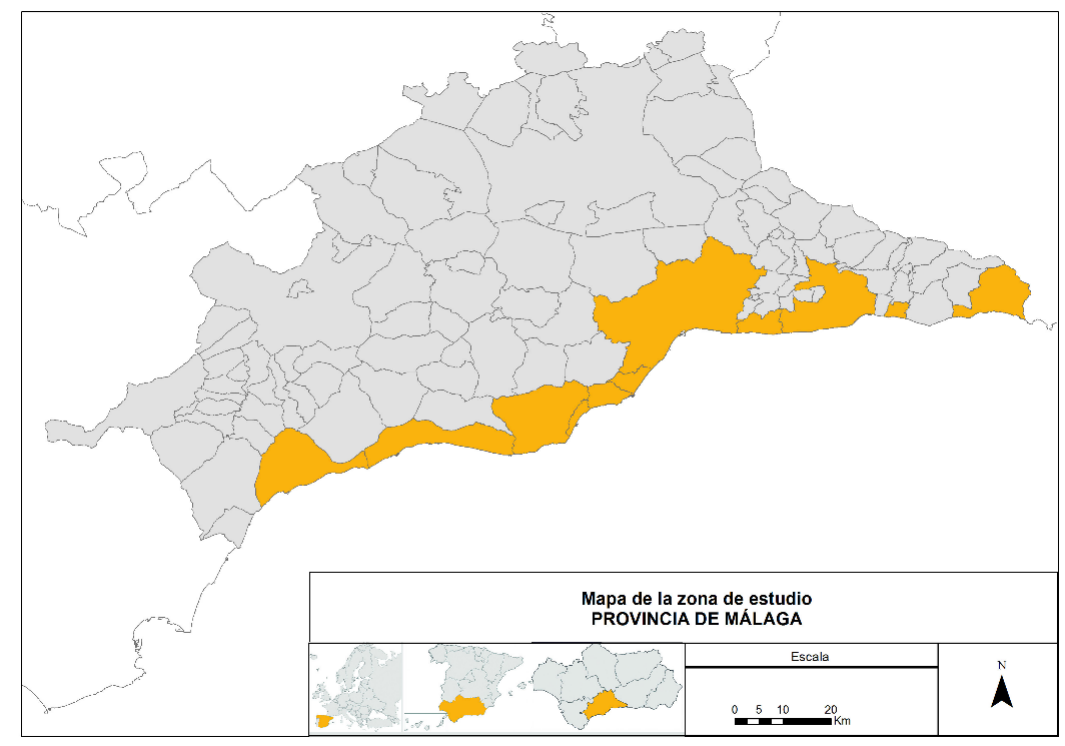

Fuente: Elaboración propia.

\section{Aspectos metodológicos: análisis cuantitativo}

Para el análisis cuantitativo se ha trabajado con una selección y adaptación de indicadores de creatividad (Cuadro N01) desarrollados en EE.UU. (Florida, 2004), UE (Florida and Tinagli, 2004), China (Li y Florida, 2006), Dublín (Murphy y Redmon, 2009), España (Pesquera et al., 2010) y los Países Nórdicos, especialmente Suecia (Andersen et al, 2010; Ström y Nelson, 2010) y Gran Bretaña (Clifton et al 2013). Como parte de la adaptación de los indicadores se han incluido algunos utilizados por González- Reverté (2008) en su análisis sobre el rol que han tenido los destinos turísticos en la transformación sociodemográfica del litoral mediterráneo español. La investigación se realiza a escala local para Málaga-Costa del Sol, y se comparan los resultados con los municipios de las provincias litorales del Mediterráneo, Huelva, Cádiz y las Islas Canarias (en adelante se hará referencia como Mediterráneo-Canarias) teniendo como base el estudio de González-Reverté et al. (2016).

El análisis se ha realizado sobre los municipios de más de 20.000 habitantes $^{5}$ en su mayor parte a partir de los microdatos censales de 2011, junto con los informes de la Oficina Española

Por secreto estadístico los microdatos censales, de donde se extraen la práctica totalidad de los indicadores, no están disponibles para municipios con menor población. 
de Patentes y Marcas. Se ha utilizado el método de ranking de indicadores, que consiste en establecer un ordenamiento de las variables, para normalizar y comparar variables (Schuschny y Soto, 2009):

$$
y_{t}^{i}=\operatorname{Ranking}\left(x_{t}^{i} \in X\right)
$$

Se ha establecido como criterio de ordenamiento la asignación del primer puesto del ranking al municipio con el mejor resultado en el indicador y el último valor del ranking al municipio con el peor resultado. Las variables normalizadas sin ponderar se han agregado en subíndices de Tolerancia, Tecnología y Talento siguiendo el método de agregación aditivo de ranking, esto es mediante la suma, para cada municipio, del orden obtenido en cada una de las variables (p) en relación con el resto de los municipios de la selección (Schuschny y Soto, 2009):

$$
I_{t}^{j}=\sum_{i=1}^{p} \text { Ranking }_{y_{t}^{i j}} \quad \forall 1 \leq j \leq N_{\text {municipality }}
$$

Los valores obtenidos en cada uno de los tres subíndices de Tolerancia, Tecnología y Talento, se han agregado de nuevo sin ponderar con el mismo método para obtener el índice global de creatividad.

Es preciso comentar que una de las limitaciones e inconvenientes del método de normalización por ranking es la pérdida de información ya que no toma en cuenta los valores absolutos, lo que da lugar a que no siempre coincidan los promedios de los tipos de municipios mejor posicionados con los valores. Por otra parte, para calcular los indicadores relativos a la clase creativa se ha partido de la identificación de las actividades creativas que realizan Méndez et al. (2012) para España en función de los criterios de la UNCTAD (2010) y la clasificación CNAE- 2009. Sin embargo, en este trabajo la aproximación a las actividades creativas se amplía, atendiendo a la clasificación de Florida (2004), con las actividades relacionadas con programación, consultoría y otras actividades relacionadas con la informática; investigación y desarrollo; educación; y actividades sanitarias ${ }^{6}$.

\footnotetext{
Listado de actividades según CNAE'09: 18 - Artes gráficas y reproducción de soportes grabados; 58 - Edición; 59 - Actividades cinematográficas, de vídeo y de programas de televisión, grabación de sonido y edición musical; 60 - Actividades de programación y emisión de radio y televisión; 62 - Programación, consultoría y otras actividades relacionadas con la informática; 71 - Servicios técnicos de arquitectura e ingeniería; ensayos y análisis técnicos; 72 - Investigación y desarrollo; 73 - Publicidad y estudios de mercado; 74 - Otras actividades profesionales, científicas y técnicas; 85 - Educación; 86 - Actividades sanitarias; 90 - Actividades de creación, artísticas y espectáculos; 91 - Actividades de bibliotecas, archivos, museos y otras actividades culturales.
} 


\section{Cuadro $\mathrm{N}^{\circ} 1$}

Indicadores de creatividad y criterio de interpretación

\begin{tabular}{|c|c|c|c|c|c|}
\hline Tipo & ID & Indicador & Antecedentes & $\begin{array}{c}\text { Descripción proxy } \\
\text { seleccionado }\end{array}$ & Criterio \\
\hline \multirow{6}{*}{ Tolerancia } & TO1 & Homosexualidad & $\begin{array}{l}\text { US_Florida (2004), Dublin_Mur- } \\
\text { phy\&Redmon (2009), Sweden_ } \\
\text { Ström \& Nelson (2010), Spain_ } \\
\text { Pesquera et al. (2010) }\end{array}$ & $\begin{array}{l}\text { Población con pareja } \\
\text { del mismo sexo / total } \\
\text { población }\end{array}$ & $\begin{array}{l}\text { Más, } \\
\text { mejor }\end{array}$ \\
\hline & TO2 & $\begin{array}{c}\text { Diversidad } \\
\text { cultural }\end{array}$ & $\begin{array}{l}\text { US_Florida (2004), Dublin_Mur- } \\
\text { phy\&Redmon (2009), Swe- } \\
\text { den_Ström \& Nelson (2010), } \\
\text { Spain_Pesquera et al.(2010), Swe- } \\
\text { den\&UK_Clifton et al (2012), The } \\
\text { Nordics_Andersen et al (2010), }\end{array}$ & $\begin{array}{l}\text { Población nacida en el } \\
\text { extranjero / total po- } \\
\text { blación }\end{array}$ & $\begin{array}{l}\text { Más, } \\
\text { mejor }\end{array}$ \\
\hline & TO3 & $\begin{array}{l}\text { Actividades } \\
\text { artísticas }\end{array}$ & $\begin{array}{l}\text { US_Florida (2004), Sweden_ } \\
\text { Ström \& Nelson (2010), Spain_ } \\
\text { Pesquera et al. (2010), The Nor- } \\
\text { dics_Andersen et al (2010) }\end{array}$ & $\begin{array}{l}\text { Artistas, escritores y } \\
\text { profesiones similares / } \\
\text { población activa }\end{array}$ & $\begin{array}{l}\text { Más, } \\
\text { mejor }\end{array}$ \\
\hline & TO4 & $\begin{array}{l}\text { Diversidad de } \\
\text { género en el } \\
\text { empleo }\end{array}$ & González-Reverté (2008) & $\begin{array}{l}\text { Ratio de hombres/ } \\
\text { mujeres que ocupan } \\
\text { cargos de dirección o } \\
\text { gerencia }\end{array}$ & $\begin{array}{l}\text { Menos, } \\
\text { mejor }\end{array}$ \\
\hline & TO5 & $\begin{array}{l}\text { Parejas de } \\
\text { hecho }\end{array}$ & González-Reverté (2008) & $\begin{array}{l}\text { Población que vive } \\
\text { con pareja de hecho / } \\
\text { total población }\end{array}$ & $\begin{array}{l}\text { Más, } \\
\text { mejor }\end{array}$ \\
\hline & TO6 & $\begin{array}{c}\text { Hogares } \\
\text { monoparentales }\end{array}$ & González-Reverté (2008) & $\begin{array}{l}\text { Población que vive en } \\
\text { hogares monoparen- } \\
\text { tales / total población }\end{array}$ & $\begin{array}{l}\text { Más, } \\
\text { mejor }\end{array}$ \\
\hline \multirow{4}{*}{ Tecnología } & TE1 & $\begin{array}{c}\text { Innovación en } \\
\text { patentes }\end{array}$ & $\begin{array}{l}\text { US_Florida (2004), UE_Florida \& } \\
\text { Tinagli (2004), China_Li \& Florida } \\
\text { (2006), Sweden_Ström \& Nel- } \\
\text { son (2010), Spain_Pesquera et al. } \\
(2010)\end{array}$ & $\begin{array}{l}\text { Patentes concedidas / } \\
\text { total población }\end{array}$ & $\begin{array}{l}\text { Más, } \\
\text { mejor }\end{array}$ \\
\hline & TE2 & $\begin{array}{l}\text { Innovación en } \\
\text { modelos de } \\
\text { utilidad }\end{array}$ & - & $\begin{array}{l}\text { Modelos de utilidad } \\
\text { concedidos / total po- } \\
\text { blación }\end{array}$ & $\begin{array}{l}\text { Más, } \\
\text { mejor }\end{array}$ \\
\hline & TE3 & Tecnología & $\begin{array}{l}\text { Sweden\&UK_Clifton et al (2012), } \\
\text { Sweden_Ström \& Nelson (2010); } \\
\text { The Nordics_Andersen et al } \\
\text { (2010); US_Florida (2004) }\end{array}$ & $\begin{array}{l}\text { Población en activida- } \\
\text { des de alta y media-al- } \\
\text { ta tecnología (no in- } \\
\text { cluye I+D) / población } \\
\text { activa }\end{array}$ & $\begin{array}{l}\text { Más, } \\
\text { mejor }\end{array}$ \\
\hline & TE4 & $I+D$ & $\begin{array}{l}\text { UE_Florida \& Tinagli (2004), } \\
\text { Spain_Pesquera et al. (2010), The } \\
\text { Nordics_Andersen et al (2010) }\end{array}$ & $\begin{array}{l}\text { Población en activida- } \\
\text { des de I+D / población } \\
\text { activa }\end{array}$ & $\begin{array}{l}\text { Más, } \\
\text { mejor }\end{array}$ \\
\hline
\end{tabular}




\begin{tabular}{|c|c|c|c|c|c|}
\hline Tipo & ID & Indicador & Antecedentes & $\begin{array}{l}\text { Descripción proxy } \\
\text { seleccionado }\end{array}$ & Criterio \\
\hline \multirow{6}{*}{ Talento } & TA1 & $\begin{array}{c}\text { Capital humano } \\
\text { (titulados } \\
\text { universitarios) }\end{array}$ & $\begin{array}{l}\text { US_Florida (2004), UE_Florida \& } \\
\text { Tinagli (2004), Sweden_Ström \& } \\
\text { Nelson (2010), Spain_Pesquera et } \\
\text { al. (2010), Sweden\&UK_Clifton et } \\
\text { al (2012), The Nordics_Andersen } \\
\text { et al (2010) }\end{array}$ & $\begin{array}{l}\text { Población con estu- } \\
\text { dios universitarios / } \\
\text { total población }\end{array}$ & $\begin{array}{l}\text { Más, } \\
\text { mejor }\end{array}$ \\
\hline & TA2 & Doctores & & \begin{tabular}{|l|} 
Población con estu- \\
dios de doctorado fi- \\
nalizados / población
\end{tabular} & $\begin{array}{l}\text { Más, } \\
\text { mejor }\end{array}$ \\
\hline & TA3 & $\begin{array}{c}\text { Atracción de } \\
\text { capital humano }\end{array}$ & Italia_Tinagli\&Florida (2006) & \begin{tabular}{|l|} 
Porcentaje de pobla- \\
ción extranjera con \\
estudios superiores / \\
total universitarios
\end{tabular} & $\begin{array}{l}\text { Más, } \\
\text { mejor }\end{array}$ \\
\hline & TA4 & Emprendimiento & $\begin{array}{l}\text { Sweden\&UK_Clifton et al (2012) } \\
\text { [adaptado del indicador de crea- } \\
\text { ción de empresas] }\end{array}$ & $\begin{array}{l}\text { Empresarios y profe- } \\
\text { sionales que emplean } \\
\text { personal / Población } \\
\text { activa }\end{array}$ & $\begin{array}{l}\text { Más, } \\
\text { mejor }\end{array}$ \\
\hline & TA5 & Clase creativa & $\begin{array}{l}\text { UE_Florida \& Tinagli (2004), } \\
\text { Spain_Pesquera et al. (2010), Swe- } \\
\text { den\&UK_Clifton et al (2012), The } \\
\text { Nordics_Andersen et al (2010) }\end{array}$ & $\begin{array}{l}\text { Población en activida- } \\
\text { des de clase creativa } \\
\text { (CNAE) / población } \\
\text { activa }\end{array}$ & $\begin{array}{l}\text { Más, } \\
\text { mejor }\end{array}$ \\
\hline & TA6 & $\begin{array}{l}\text { Atracción de } \\
\text { clase creativa }\end{array}$ & Italia_Tinagli\&Florida (2006) & \begin{tabular}{|l|} 
Extranjeros creativos / \\
total creativos
\end{tabular} & $\begin{array}{l}\text { Más, } \\
\text { mejor }\end{array}$ \\
\hline Creatividad & & $\begin{array}{c}\text { Índice global de } \\
\text { creatividad }\end{array}$ & & $\begin{array}{l}\text { Combinación de los } \\
\text { índices de tolerancia, } \\
\text { tecnología y talento }\end{array}$ & $\begin{array}{l}\text { Más, } \\
\text { mejor }\end{array}$ \\
\hline
\end{tabular}

Fuente: Elaboración propia.

\section{Aspectos metodológicos: análisis cualitativo}

La visión sobre la realidad procedente de los propios actores ayudará a contrastar, comprender y enriquecer las motivaciones que inducen a la atracción de la clase creativa a un determinado lugar, y en concreto, los elementos existentes en un destino turístico que pueden influir en dichos factores de atracción. De manera más específica se persigue profundizar en las motivaciones de localización de los profesionales creativos, contrastándolas con los factores de ubicación identificados por Florida $(2004,2010)$ y evaluar si existen factores de atracción relacionados con el desarrollo de un destino turístico.

La técnica cualitativa elegida ha sido la entrevista semiestructurada (Vela Peón, 2001) basada en un guion. Se han realizado un total de 44 entrevistas a dos tipos de informantes: 13 informantes clave y 31 informantes directos. Los informantes clave se han seleccionado mediante el muestreo no probabilístico-intencional, que han constituido las unidades de relevamiento iniciales (Merlos, Rodríguez y Otero, 2014). Son personas seleccionadas por su conocimiento de la realidad empresarial, profesional y/o académica del área de estudio, se trata de expertos de diferentes entidades 
públicas y privadas relacionadas con turismo o emprendimiento: Consorcio Qualifica-Costa del Sol; Consejería de Turismo y Comercio de la Junta de Andalucía; Confederación de Empresarios de Málaga; Cámara de Industria, Comercio y Navegación de Málaga; Asociación de Jóvenes Empresarios de Málaga; Parque Tecnológico de Andalucía; Mancomunidad de Municipios de la Axarquía-Costa del Sol; Asociación Española de Expertos Científicos en Turismo, Universidad de Málaga; Ecosistema emprendedor de la Costa del Sol. Seguidamente se han entrevistado a los informantes directos identificados mediante muestreo no probabilístico-en bola de nieve a partir de los informantes clave y de otros informantes directos. Los informantes directos son personas que cumplen el perfil de clase creativa, residente en algún municipio de la provincia de Málaga. Las entrevistas se han realizado entre los meses de enero de 2015 y septiembre de 2015 y se han registrado en soporte de audio (31 horas de grabación), complementándose con notas tomadas durante las conversaciones.

Los temas que han guiado la conversación de las entrevistas recogen percepciones acerca de la experiencia vital en la Costa del Sol, incidiendo en aspectos sobre los motivos de traslado o permanencia en la zona, la valoración de aspectos positivos y negativos, la percepción de singularidades y la percepción de influencia del desarrollo turístico en relación los motivos de ubicación (Figura $\mathrm{N}^{\circ}$ 2).

Para el análisis de la información producida, primeramente, se ha procedido a la transcripción de las grabaciones de las entrevistas y las notas tomadas durante las mismas, utilizando como apoyo el programa QSR NVivo 10. Primeramente, se ha realizado una codificación abierta, identificando ideas, conceptos o significados relevantes en nodos libres. Esto ha permitido identificar y definir, en línea con los temas tratados, las categorías centrales iniciales del análisis, generando

Figura $\mathrm{N}^{\circ} 2$

Relación entre objetivos, temas y estructura maestra de codificación.
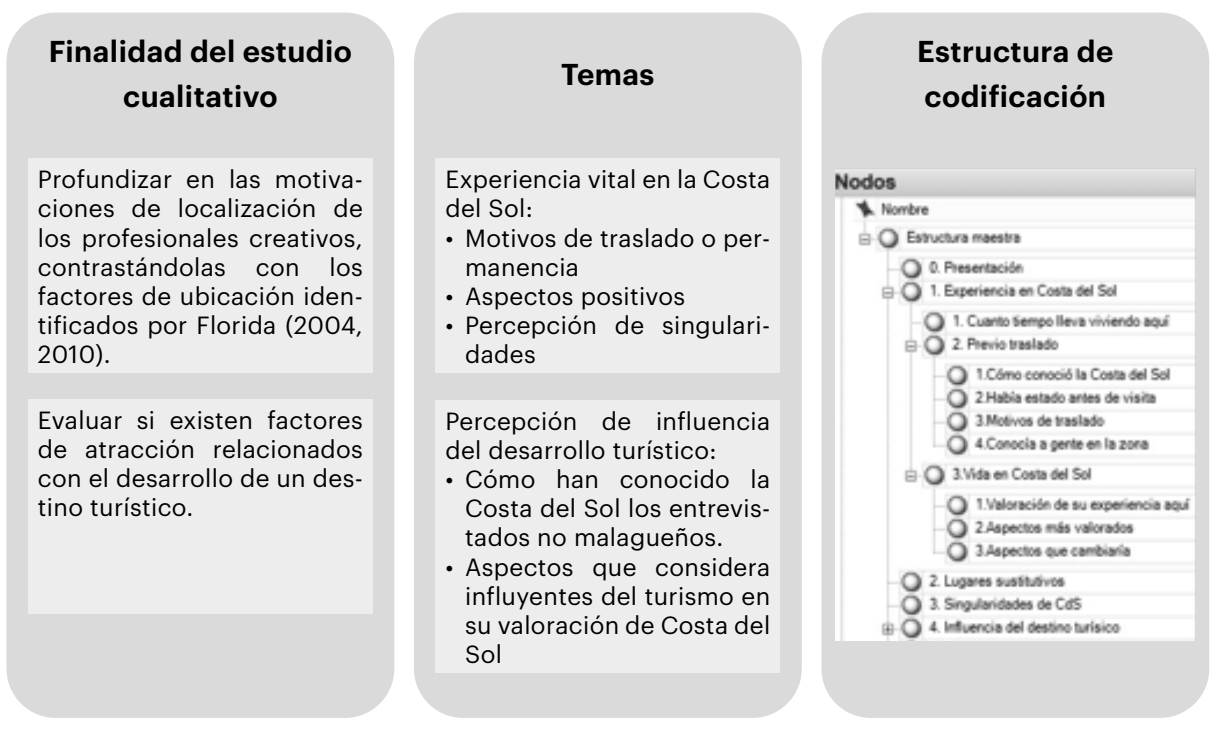

Fuente: Elaboración propia. 
la "estructura maestra" de codificación (Figura No2). En segundo lugar, se ha procedido a partir de esta estructura, a la codificación axial, ramificando los nodos desde las categorías principales hacia categorías más específicas. Por último, se ha procedido a la agrupación de nodos y análisis relacionando la información codificada con los objetivos del estudio y el marco teórico.

\section{Resultados y discusión}

\section{El Índice de Creatividad en Málaga-Costa del Sol}

Los municipios con mayor índice de creatividad en el caso de la zona que denominamos Málaga-Costa del Sol se distribuyen desde Rincón de la Victoria hasta Marbella en la composición de los tres índices de Tolerancia, Tecnología y Talento (Cuadro No2 y Figura ํo3). Aunque Málaga capital concentra las principales infraestructuras tecnológicas de conocimiento y transporte (Parque Tecnológico, Universidad, aeropuerto, ferrocarril y puerto), el desarrollo turístico hace que no tenga el mismo protagonismo que otras capitales de provincia cuya dinámica urbana-metropolitana se haya configurado de manera tradicional en torno a una ciudad histórica y que además habitualmente concentran funciones administrativas supraprovinciales, como es por ejemplo el caso de Sevilla. De esta manera, el Índice de Creatividad en la provincia de Málaga muestra unos valores que se extienden de manera lineal a lo largo de toda la costa $(160 \mathrm{~km})$, compartiendo con la capital el papel de motor de influencia hacia las zonas de interior. A diferencia de las áreas metropolitanas convencionales, la Costa del Sol no dispone de un solo núcleo de influencia, sino que es policéntrica.

Este hecho influye en el comportamiento de los subíndices de tolerancia, tecnología y talento. Se observa muy claramente cómo los indicadores que se asocian a Tecnología presentan mejores resultados en la capital donde se concentran las infraestructuras relacionadas con tecnología e innovación y los municipios incluidos en su aglomeración como es el caso de Rincón de la Victoria, Torremolinos y Benalmádena. Sin embargo, para el caso de los indicadores relacionados con tolerancia y talento, destacan de manera clara los municipios con un desarrollo turístico más consolidado, tales como Torremolinos, Mijas, Marbella, Benalmádena o Fuengirola. Además, en estos dos subíndices la zona Málaga-Costa del Sol supera el promedio resultante en las provincias del Mediterráneo y Canarias (Romero-Padilla, 2016). Cabe pensar que ambos subíndices se retroalimentan pues la tolerancia muestra una sociedad abierta al cambio y a la acogida de personas algo esencial para la atracción del talento. Algunos de los indicadores que más destacan si se comparan con el resto del Mediterráneo son por ejemplo el de homosexualidad con Torremolinos en la sexta posición con aproximadamente 8 parejas homosexuales por cada 1.000 habitantes o Mijas con algo más de 4\% parejas/hab. (Romero-Padilla, 2016). También destacan en diversidad cultural con una elevada presencia de población extranjera, como es el caso de Fuengirola que ocupa el decimotercer puesto en el conjunto del Mediterráneo y las Canarias, o Mijas, Nerja y Torremolinos que se sitúan por encima de la posición 25. Finalmente, algunos municipios ocupan posiciones destacables en los indicadores de capital humano, la presencia de doctores o de emprendedores, pero sin duda, los indicadores más llamativos corresponden a la atracción de capital humano y creativo extranjeros donde los municipios de la Costa del Sol Occidental ocupan posiciones avanzadas superando una proporción del 20\% (y en casos como Fuengirola, Mijas o Nerja superan el $30 \%$ ) de extranjeros que llegan con estudios universitarios y por encima del $15 \%$ de extranjeros cuya ocupación les engloba dentro de la clase creativa. 


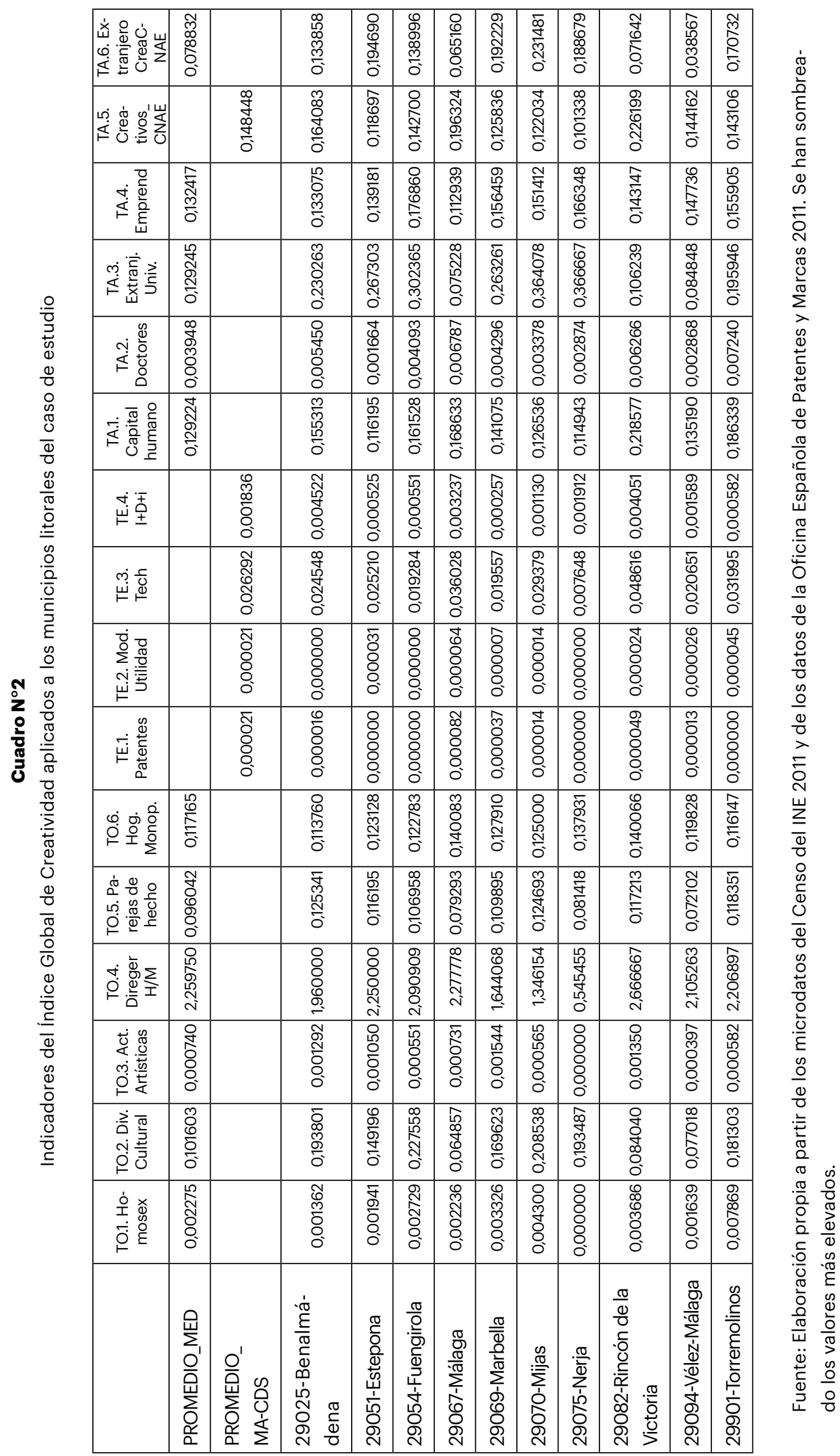


La dinámica que sigue el índice de creatividad en la Costa del Sol es similar a la observada en otras provincias del mediterráneo español y las Islas Canarias donde el turismo ha sido motor del desarrollo socio-urbano (González-Reverté, 2008). Esta dinámica se produce en zonas que combinan aglomeraciones urbanas importantes con destinos turísticos internacionales como es el caso del eje Barcelona-Costa Dorada; la costa suroeste de Mallorca o el eje Valencia-Costa Blanca (González-Reverté, et al. 2016). La Costa del Sol, al igual que estos destinos, nació como uno de los polos de desarrollo turístico planificados en los años sesenta por el gobierno central. Estos polos de desarrollo turístico han ido acompañados de dos elementos clave (Romero-Martínez, Romero-Padilla, Navarro-Jurado, 2015): (1) inversión pública en infraestructuras de transporte que ha posibilitado el desarrollo del aeropuerto y más recientemente su expansión con una segunda pista, el puerto de cruceros, el ferrocarril convencional y posteriormente el tren de Alta Velocidad Española (AVE), el fomento de la conexión por carretera mediante autovías y autopistas; (2) desarrollo de un planeamiento territorial y urbanístico 'a la carta' que ha propiciado la expansión del sellado de suelo mediante la construcción de infraestructuras turísticas y la construcción residencial, en muchas ocasiones ilegales o de dudosa legalidad (un caso representativo es Marbella, el primer ayuntamiento democrático de España disuelto por motivos de corrupción).

En general y en sintonía con el resto del arco mediterráneo, la Costa del Sol se muestra como un lugar tolerante y abierto, que resulta atractivo para vivir tanto para la población que busca mejores condiciones climáticas para pasar su jubilación como para el capital humano y creativo que acude a la zona. Para ahondar mejor en las motivaciones de este capital creativo y en la influencia que el desarrollo turístico ha podido tener sobre el comportamiento del índice de creatividad, en el siguiente apartado se profundiza desde una visión cualitativa contrastada de manera pormenorizada con los indicadores de cada subíndice.

Figura $\mathrm{N}^{\circ} 3$

Mapa de resultados del Índice de Creatividad en Málaga-Costa del Sol

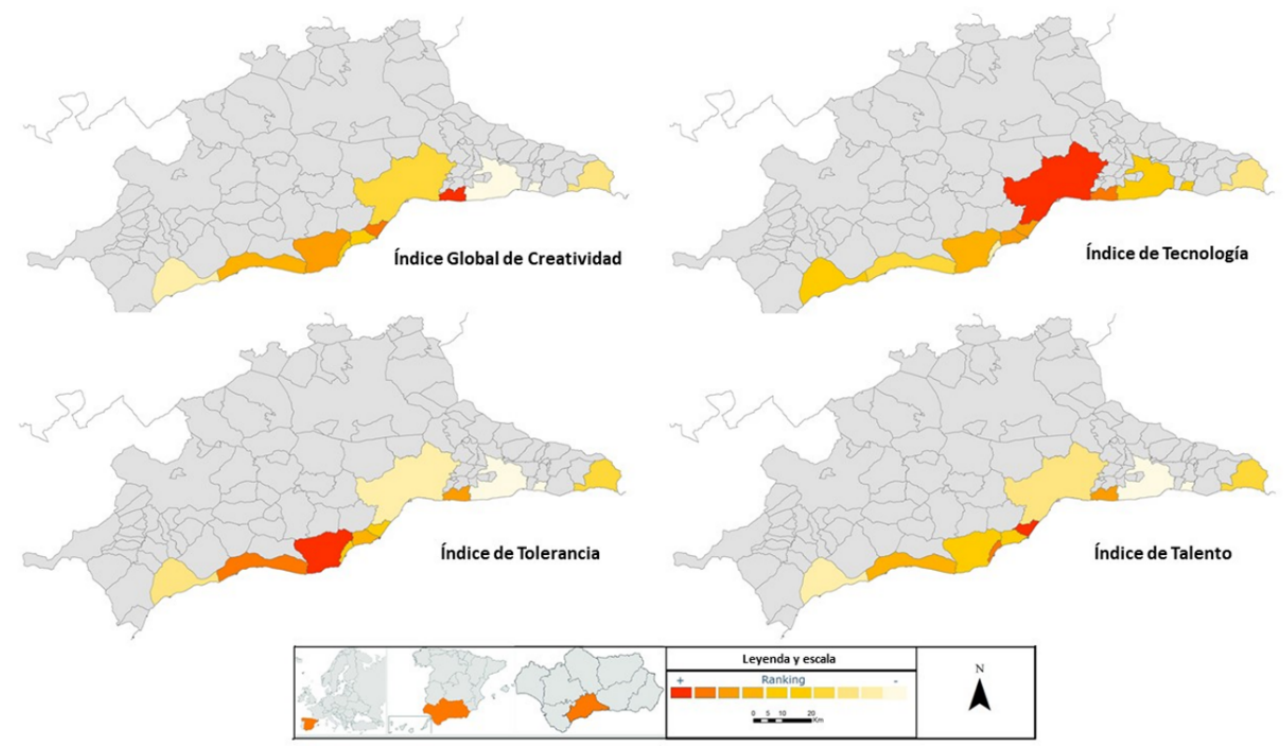

Fuente: Elaboración propia. 


\section{Vivir y trabajar en Málaga-Costa del Sol}

Los tres aspectos más valorados por los entrevistados en Málaga-Costa del Sol son el clima $\left(26 / 44^{7}\right)$, la calidad de vida (21/44) y la gente (16/44) de una manera interrelacionada. Al clima asocian otros aspectos como un ambiente alegre, la posibilidad de hacer vida en la calle durante todo el año, poder disfrutar de un ambiente de vacaciones los fines de semana o la facilidad de relacionarse. Esto se explica por la localización de la Costa del Sol dentro de la zona templada del planeta, con un clima Mediterráneo que, en general, presenta temperaturas anuales suaves, amplitud térmica moderada y precipitaciones anuales irregulares y escasas. Estas condiciones climáticas posibilitan un mayor aprovechamiento de las actividades al aire libre a lo largo de todo el año en comparación con otros lugares de España, pero sobre todo con los países de residencia de algunos de los entrevistados (Holanda, Finlandia, Rumanía, Irlanda, Bélgica, Reino Unido, Hungría...).

Otro aspecto valorado es la "gente" que se vincula con cualidades como agradable, amable, sencilla, abierta, hospitalaria, alegre, solidaria o dispuesta a comunicarse. En sintonía con el resto del arco mediterráneo, la Costa del Sol se muestra como un lugar atractivo para los migrantes por estilos de vida (Benson y O'Reilly, 2009). Sus municipios aglutinan las proporciones más elevadas de extranjeros censados de toda Andalucía (la mitad de los municipios costeros superan el $15 \%$ de extranjeros y algunos como Mijas y Fuengirola sobrepasan el 20\%). Lo mismo ocurre con el resto de los indicadores. La presencia de homosexuales en municipios como Torremolinos (7'9\%o), Mijas $\left(4^{\prime} 7 \%\right.$ ), Rincón de la Victoria (3'7\%o) o Marbella (3'3\%) presentan valores superiores a la media de Andalucía (1'7\%o). En los indicadores de parejas de hecho y hogares monoparentales se observa una situación similar. Si los promedios en Andalucía se sitúan en 7’5\% parejas de hecho respectivamente y en torno al $111^{\prime} 5 \%$ respecto a los hogares monoparentales, los municipios litorales malagueños se vuelven a situar por encima en ambos casos, con excepción de Benalmádena en el indicador de hogares monoparentales que se queda unas décimas por debajo.

La calidad de vida también aparece asociada con otros aspectos como un ritmo más relajado, vivir más el momento, no planificar tanto la vida personal o una buena combinación del desarrollo profesional y el disfrute de la vida. Otros aspectos que los entrevistados citan como importantes son la conectividad internacional y nacional (13/44) y el entorno físico natural (11/44) relativo al mar, cercanía de la montaña, diversidad de paisajes y posibilidades de ocio. En el caso de Málaga-Costa del Sol, ha sido y sigue siendo motor de desarrollo socioeconómico en la región andaluza. En esta zona se ubica el aeropuerto más importante de Andalucía y el cuarto de España con un tráfico que se acerca a los 17 millones de pasajeros en 2016 (más de 14 millones procedentes de vuelos internacionales) y con conexiones a más de 100 destinos, incluyendo vuelos transcontinentales a EE.UU. También cuenta con importantes conexiones en AVE hacia Madrid (duración media inferior a 3 horas y una frecuencia media de 16 trenes al día) que facilitan las relaciones profesionales y de negocios con la capital. También el tráfico marítimo es un punto a tener en cuenta, más allá del tráfico de cruceros que está directamente relacionado con los viajes turísticos, pues posibilita las conexiones con Marruecos vía Melilla. 
En el momento de abordar la pregunta sobre si consideran que Málaga-Costa del Sol tiene algún elemento que la hace singular, aparecen aspectos que se añaden a los ya mencionados clima (10/44) y calidad de vida (5/44), como es el ambiente cosmopolita (9/44) y la apertura y tolerancia (7/44). Sin embargo, la mayor parte de los entrevistados no aluden a un solo factor, de hecho, hasta ocho de los entrevistados remarcan expresamente que es la presencia a la vez de varios factores lo que hace que les resulte un lugar singular en comparación con otras zonas. En concreto la singularidad que destacan de Málaga-Costa del Sol se expresa como la combinación de diferentes aspectos que permiten el equilibrio entre disfrutar de calidad de vida (clima, gente, ciudad abierta al mar, entorno, coste de vida más barato, comodidad en la movilidad, multiculturalidad) y las posibilidades de desarrollar trabajo profesional y/o negocios (infraestructuras de comunicación, aeropuerto, AVE, entorno emprendedor, potencial humano, Parque Tecnológico, infraestructuras de apoyo a emprendedores). En investigaciones anteriores se puso en evidencia el papel como motor de desarrollo urbano y socioeconómico que los municipios turísticos habían ejercido en el mediterráneo español (González-Reverté, 2008). En el caso de los estudios específicos sobre la relación entre el índice de creatividad y el grado de desarrollo turístico (González-Reverté, et al. 2016), también demuestran cómo la creatividad se concentra en grandes aglomeraciones urbano-turísticas, lo que incluye destinos de relevancia internacional y nacional y capitales de provincia que, tradicionalmente en el caso español, han concentrado las infraestructuras de transporte, de desarrollo tecnológico y de gestión del conocimiento.

En relación con esto, otro factor relevante para el desarrollo profesional es el tejido empresarial existente. En la provincia de Málaga se concentran en torno al 25\% de las empresas de Andalucía. Si bien el comercio, la hostelería y la construcción son sectores importantes también lo es el impulso al desarrollo de empresas con base tecnológica y en el conocimiento. En la capital malagueña se localiza el Parque Tecnológico de Andalucía, que es además sede de la Asociación Internacional de Parques Científicos y Tecnológicos (IASP), la Asociación de Parques Científicos y Tecnológicos de España (APTE) y la Red de Espacios Tecnológicos de Andalucía (RETA). Otra infraestructura relacionada, aunque todavía en fase incipiente de desarrollo, es el Parque Tecno-alimentario Costa del Sol-Axarquía, con efectos aún bastante locales, principalmente en la comarca de la Axarquía, pero que constituye un impulso para el desarrollo de la industria agroalimentaria.

Los elementos señalados anteriormente se vuelven a observar en los motivos que influyeron en la decisión de traslado de los profesionales creativos procedentes de fuera de la provincia. Además de los factores reiterativos del clima y en general el entorno (6/22 en ambos casos) consideraron importantes la dinámica empresarial y emprendedora, incluyendo aspectos como las oportunidades de empleo y negocio (9/22), el ambiente internacional (5/22), y la conectividad principalmente por disponer de un aeropuerto importante (3/22). Lo mismo ocurre con el caso de los creativos malagueños cuya decisión de vuelta o permanencia queda ligada a la posibilidad de desarrollar su carrera profesional o negocio en la provincia. Éstos coinciden con los creativos foráneos en la importancia de las conexiones que tiene la Costa del Sol, así como del entorno empresarial del Parque Tecnológico y el capital humano que facilita la Universidad de Málaga.

En definitiva, la presencia de los componentes de la triple hélice de la innovación es importante para atraer y retener a estos creativos haciendo que opten por esta zona por encima de otras opciones en Andalucía (Granada o Almería) o España (Valencia o Murcia). Si bien el grado de desarrollo no es equiparable a una ciudad global, en lugar de percibirse como una barrera 
los entrevistados relacionados con el ecosistema emprendedor ${ }^{8}$ lo consideran una oportunidad, aludiendo a razones como una menor saturación empresarial (menor competencia), mayores posibilidades de creación y desarrollo de negocios y poder competir en un mercado global con precios competitivos por situarse en una zona con menor coste de vida y producción respecto a otras zonas de Europa o de EEUU.

Todo ello contribuye a explicar que las aglomeraciones urbano-turísticas sean atractivas para la atracción de talento, como muestran los indicadores de capital humano, emprendedor y creativo. Así mientras la proporción media de capital humano en Mediterráneo-Canarias se sitúa en torno a un 13\%, en el núcleo de la Costa del Sol (Torremolinos, Benalmádena, Fuengirola, Marbella) alcanza en torno a un 14-18'6\%. La proporción de población activa emprendedora muestra unos valores por encima del $15 \%$ en municipios como Fuengirola (17'7\%), Nerja (16'6\%), Marbella (15'6\%) y Torremolinos (15'6\%) frente a la proporción media de la región (13'2\%). Respecto a la proporción de capital creativo la media del conjunto de Málaga-Costa del Sol (14'4\%) se encuentra cercana al promedio mediterráneo (15'2\%) con algunos municipios que la superan como Benalmádena (16'4\%) o Rincón de la Victoria (22'6\%). Pero lo que llama más la atención es la atracción de capital humano y creativo extranjeros, ya que mientras que la proporción Mediterráneo-Canarias se sitúa en un $13 \%$ y $7{ }^{\prime} 8 \%$ respectivamente, en municipios como Torremolinos, Benalmádena, Fuengirola, Mijas o Marbella se sitúan entre el $20-36^{\prime} 7 \%$ en el caso del capital humano extranjero y entre el $13^{\prime} 4-23^{\prime} 1 \%$ en el caso del capital creativo extranjero.

\section{Influencia del desarrollo turístico en la atracción y/o retención de clase creativa}

Existe bastante consenso a la hora de señalar tres de los aspectos que más se han visto favorecidos por el turismo. Primero, señalan al turismo como vertebrador de las infraestructuras de transporte y de otras infraestructuras y servicios urbanos públicos y privados (oferta cultural, educativa, sanitaria, de ocio...). Las dimensiones de estas infraestructuras no atienden al volumen de población local residente sino al volumen de turistas, por lo que los residentes se benefician de ello y hace viable que puedan desarrollarse profesionales y empresas creativas, tecnológicas y de otros sectores. Segundo, la apertura de la sociedad por la influencia de población procedente de otras zonas de España y del mundo y que ha permitido a la población local habituarse y adaptarse a lo diferente, así como nutrirse del conocimiento y las tendencias extranjeras. Tercero, el ambiente internacional existente, tanto por la presencia de extranjeros transeúntes como por el asentamiento progresivo de una comunidad extranjera importante, se percibe como un factor influyente en el desarrollo de una mentalidad global o internacional de la sociedad malagueña. Los tres aspectos facilitan la presencia de profesionales, muchos de ellos freelance, que eligen la zona para vivir pero manteniéndose conectados globalmente a un coste asumible, con la posibilidad añadida de tener cerca comunidades de su misma cultura o con un grado de afinidad mayor con las que trabajar y/o relacionarse.

Más de la mitad de los entrevistados procedentes de fuera de Málaga llegaron con la idea de montar un negocio propio o, aunque primeramente llegaron con un empleo, terminan montando su propia actividad empresarial. Todos los entrevistados malagueños eran emprendedores y siete de los trece informantes clave eran emprendedores o prestaban servicios de asesoramiento a emprendedores. 
Los informantes clave complementan estos aspectos con dos elementos más. La percepción del turismo como principal foco de atracción de negocio e inversiones, siendo el soporte o el potencial soporte para el desarrollo de otros sectores (inmobiliario, comercio, tecnológico...). Y el desarrollo de una imagen de la zona conocida internacionalmente a través de la marca turística Costa del Sol, lo que facilita su posicionamiento dentro de la red de funcionamiento global y su aprovechamiento para estrategias como la del Club Málaga Valley.

Examinando de manera particular cómo habían conocido la zona los creativos no nacidos en Málaga se observa que fundamentalmente ha sido por su condición de destino turístico, bien porque los entrevistados han realizado estancias previas de vacaciones durante su infancia-adolescencia (con padres y/o abuelos) o bien porque conocían la marca turística (con diferencias entre Marbella y Costa del Sol).

En este sentido se destacan tres experiencias. El primer caso explicaba que el litoral malagueño ha sido como su segunda casa pues los padres disponen de una segunda residencia en la que veranean con la familia, lo que influyó y facilitó su traslado. El segundo caso, eligió Marbella como lugar en el que pasar uno o dos meses de vacaciones por su oferta de campos de golf, sin embargo, antes de finalizar las vacaciones le surgió una oportunidad de empleo y decidió quedarse. El tercer caso, comentaba que su primera estancia de residencia en España fue Madrid, sin embargo, había pasado desde su adolescencia estancias periódicas de vacaciones en Fuengirola lo que le permitió forjar amistades con las que posteriormente emprendió un negocio que hoy en día sigue funcionando en Mijas. Si bien Larsen et al. (2007) comentan que las relaciones sociales globales que de manera recíproca se van generando entre el lugar de origen y el nuevo lugar de residencia para el caso de los inmigrantes, estos casos muestran también las relaciones que se van forjando entre el lugar del turista y el destino conforme éste repite estancias, que va incrementando también esa red de relaciones sociales globales.

En los casos en los que se planteaban el trasladado sin haber estado previamente, bien organizaron una visita previa de vacaciones que aprovechaban para hacer entrevistas de trabajo y/o conocer la zona como paso final en el proceso de toma de decisión del traslado (en el caso de extranjeros comienzan trabajando o haciendo entrevistas de trabajo en empresas extranjeras ya localizadas en la zona), o bien ya disponían de lazos de amistad o familiares en Málaga-Costa del Sol o en otras provincias cercanas de Andalucía (ej. padres o pareja de origen español o amigos que se han trasladado ya a la zona a vivir).

Finalmente, cabe mencionar tres temas preocupantes señalados por parte de informantes clave y creativos malagueños en relación con el hecho de ser un destino turístico. El primero, tiene que ver con el coste de oportunidad, el buen funcionamiento del sector turístico hace que no se inviertan esfuerzos en otras opciones de desarrollo en la provincia en general y en concreto en la Costa del Sol Occidental, incluso se percibe que es necesaria una mayor coordinación entre agentes para liderar una estrategia de futuro común. El segundo tema se centra en la marca Costa del Sol, que principalmente se asocia al atractivo turístico y no tanto a las oportunidades de negocio, al desarrollo empresarial o a la tecnología, aunque se está trabajando en un cambio de imagen y la marca Málaga está adquiriendo protagonismo propio, todavía supone un hándicap para las relaciones de negocio externas. El tercer tema, engloba la percepción de falta de visión por parte del empresario tradicional del sector turístico para facilitar un espacio embrionario 
adecuado al desarrollo de tecnología a escala global, ya que en la actualidad se considera que en el territorio no se aprovecha suficientemente la masa de usuarios para poder hacer testeos de tecnología de manera rápida.

\section{Conclusiones}

Esta investigación contribuye a dar forma a una nueva línea de investigación en la evolución de los destinos turísticos litorales, a partir de la relación entre el desarrollo turístico y la teoría de la clase creativa. Se ha mantenido un enfoque centrado en el destino turístico como territorio y enmarcado en las tendencias del mundo contemporáneo, cada vez más global, urbano, concentrado y litoralizado. Esto ha permitido mostrar un nuevo estadio posible en la evolución de los destinos turísticos litorales consolidados más allá del determinismo o el enfoque sectorial implícito en los modelos evolutivos con mayor repercusión política o académica (Ciclo de Vida del Destino Turístico, Periferias del Placer o Re-estructuración).

El trabajo indaga en la escala local de manera cuantitativa y cualitativa, centrándose en un territorio con funciones especializadas: los destinos turísticos litorales. Los resultados del experimento cuantitativo en el sur de Europa muestran que son lugares que se están empezando a convertir en espacios creativos, reproduciendo roles y formas de vida de las ciudades globales en su contexto geográfico inmediato. La comparación con el contexto mediterráneo-canario español muestra que el caso de estudio sigue una dinámica similar a otras zonas turísticas destacando en algunos indicadores. Sobresalen en los indicadores de tolerancia y muestran resultados interesantes en los indicadores de talento, por la captación de capital humano y clase creativa extranjeros, mientras que los mayores valores del índice global de creatividad se localizan en los municipios más importantes de la aglomeración urbana y la capital malagueña. Esto se explica porque de manera conjunta ofrecen una buena combinación a la vez de los índices de Tolerancia, Tecnología y Talento de Florida (2004). Resultaos similares se obtienen en el eje Barcelona-Costa Dorada, la costa suroeste de Mallorca, el eje Valencia-Costa Blanca ya estudiados por González-Reverté et al. (2016).

Los resultados de las entrevistas realizadas a creativos residentes en la Costa del Sol muestran que muchos de los aspectos señalados como potencialidades, aspectos más valorados o singularidades, coinciden con los factores que influyen en la calidad de ubicación de Florida (2004, 2010) pero donde se aprecian matices. (1) En relación con los mercados laborales densos si bien los entrevistados coinciden en destacar las oportunidades de empleo que ofrece un lugar con una dinámica empresarial de cierta densidad, el mero acceso a un puesto de trabajo no es su principal estímulo sino las posibilidades de desarrollar un negocio profesional propio o de poder acceder a un desarrollo profesional dinámico, para lo que destacan las oportunidades de desarrollo internacional que ofrece la conectividad del aeropuerto. (2) Respecto al estilo de vida la idiosincrasia que aporta una zona turística se manifiesta en una particular percepción de la calidad de vida en la que aparecen elementos muy valorados como "ambiente de vacaciones", el ritmo relajado, la oferta de ocio, el clima y sus posibilidades de desarrollar actividades al aire libre durante todo el año, el disfrute de la vida y una inercia que lleva a "vivir más el momento". (3) Muchas de las características asociadas al estilo de vida son las que facilitan también una mayor interacción social, ya que al clima y a la vida en la calle, al ambiente de vacaciones y al ritmo relajado, se le une también 
una población que se califica de agradable, abierta y comunicativa. (4) La diversidad, principalmente se explica porque el desarrollo turístico ha contribuido a configurar una sociedad tolerante, abierta y de ambiente internacional, lo que queda confirmado en los indicadores cuantitativos referentes a la alta proporción de población extranjera, de presencia de parejas homosexuales, un mayor grado de acceso de las mujeres a los puestos de mando o las diferentes estructuras en los hogares. (5) Finalmente la autenticidad queda reflejada en el elemento que los entrevistados destacan como singular de la zona Málaga-Costa del Sol, y es la presencia a la vez de una combinación del conjunto de factores anteriormente mencionados, lo que posibilita el equilibrio que perciben los entrevistados entre las posibilidades de desarrollo de la vida profesional orientada al mercado global con la vida hedonista orientada al disfrute del placer y de la calidad de vida.

En definitiva, este cambio de rol que puede observarse especialmente en determinados destinos turísticos litorales consolidados con una elevada demanda internacional los convierte en zonas de transición entre la ciudad global y el territorio local. Es decir, no son bordes ni periferias de la ciudad global (el rol que convencionalmente se les ha venido asignando) sino que forman parte del mismo mecanismo funcional, son "ecotonos socioeconómicos glocales". De ahí su vitalidad y su contemporaneidad. Son lugares que mezclan las tendencias globales de los atributos de los estilos de vida y del espacio urbano contemporáneo con las formas de vida y asentamientos tradicionales locales, lo que afecta a las condiciones de funcionamiento del territorio y espacio urbano, de la economía, de la sociedad, de la política y de la movilidad. Por eso son atractivos para la clase creativa.

Las conclusiones abren nuevas reflexiones, que pueden ser líneas de investigación futuras. En la metodología se debe seguir avanzando en la identificación y adaptación de indicadores más específicos para destinos turísticos, lo que permitiría tener en cuenta las peculiaridades del nuevo contexto. Algunos de los indicadores son mejorables, es el caso de las patentes o los de los indicadores relacionados con I+D, de manera que permitan incluir o detectar procesos de innovación no formales que permanecen 'ocultos' en las estadísticas y son difíciles de medir en términos de inversión y resultados. Por otra parte, es interesante contrastar los indicadores de creatividad con otros indicadores económicos tradicionales en los destinos turísticos. Es importante mencionar que el propio Florida (2004) introdujo el índice de desigualdad para medir su correlación con el índice de creatividad. Como resultado obtuvo una correlación fuerte, cuanto mayor es el índice de creatividad, mayor es el de desigualdad. Este hecho, entre otras cuestiones, le ha llevado al propio Florida a revisar la teoría de la clase creativa y sus impactos (Florida, 2017). Es importante avanzar en esta relación creatividad-desigualdad, dado la buena prensa y la inversión económica que algunos territorios están realizando para atraer el capital creativo.

En relación con el refuerzo de las políticas turísticas y de regeneración urbana para el desarrollo sostenible de los destinos turísticos, sería interesante incluir indicadores específicos para medir y comparar la relación entre creatividad y sostenibilidad. Por último, es interesante introducir un sistema de ponderaciones para asignar pesos a los indicadores en función de su incidencia en la medición del potencial creativo de una zona, y específicamente de una zona turística. Respecto a los aspectos del experimento cualitativo, es interesante ampliar en trabajos futuros los casos estudiados con otras tipologías de actores que permitan indagar en las percepciones de los creativos precarios. La metodología de bola de nieve tiene la limitación de no poder controlar de manera directa a los entrevistados y, por tanto, el perfil concreto, habiéndose percibido en 
esta investigación una tendencia hacia la recomendación de contactos que aportan una visión positiva y de éxito. También pueden combinarse otras metodologías cualitativas como los grupos focalizados para evaluar las diferencias de discurso al pasar desde el plano personal al colectivo o plano público.

\section{Agradecimientos}

Los proyectos de investigación en los que se fundamenta esta investigación han sido financiados por el Programa Estatal de I+D+i Orientada a los Retos de la Sociedad del Ministerio de Ciencia, Innovación y Universidades de España: "Overtourism in Spanish coastal destinations. Tourism degrowth strategies. An approach from the social dimension" (RTI2018-094844-B-C33) y por el Campus de Excelencia Internacional Andalucía Tech promovido por las universidades de Sevilla y Málaga (España) dentro del polo de innovación "Turismo y desarrollo territorial": "Metamorfosis de una invención. Turismo y clase creativa: el caso de la Costa del Sol en el mediterráneo español".

\section{Referencias bibliográficas}

AGARWAL, S. Restructuring seaside tourism: the resort lifecycle. Annals of tourism research, 2002, Vol. 29, No 1, p. 25-55. Disponible en Internet: https://doi.org/10.1016/S0160-7383(01)00002-0

AGARWAL, S. Global-local interactions in English coastal resorts: Theoretical perspectives. Tourism Geographies, 2005, Vol. 7, No 4, p. 351-372. Disponible en Internet: https://doi. org/10.1080/14616680500291147

AGARWAL, S. Relational spatiality and resort restructuring. Annals of Tourism Research, 2012, Vol. 39, No 1, p. 134-154. Disponible en Internet: https://doi.org/10.1016/j.annals.2011.05.007

ANDERSEN, K. V., HANSEN, H. K., ISAKSEN, A. \& RAUNIO, M. Nordic City Regions in the Creative Class Debate - Putting the Creative Class Thesis to a Test, Industry and Innovation, 2010, Vol. 17, No 2, p. 215-240. Disponible en Internet: https://doi.org/10.1080/13662711003633496

ANTÓN CLAVÉ, S. Dinámicas de reestructuración de los destinos turísticos litorales del mediterráneo. Perspectivas y condicionantes. En LÓPEZ OLIVARES, D. (Coord.) Renovación de destinos turísticos consolidados, Castellón: Tirant lo Blanch, 2011, p. 23-40.

BAUMAN, Z. Tiempos líquidos. Vivir en una época de incertidumbre. España: Tusquets Editores SA, 2013 (4a Edición).

BENSON, M., \& O'REILLY, K. Migration and the search for a better way of life: a critical exploration of lifestyle migration. The Sociological Review, 2009, Vol.57, No 4, p. 608-625. Disponible en Internet: https://doi.org/10.1111/j.1467-954X.2009.01864.x 
BERRY, M. Melbourne - Is there Life after Florida? Urban Policy and Research, 2005, Vol. 23, № 4, 2005, p. 381-392. Disponible en Internet: https://doi.org/10.1080/08111470500354208

BORJA, J. \& CASTELLS, M. Local and Global: The Management of Cities in the Information Age. London: Earthscan Publications Limited, 1997.

BOURDIEU, P. The forms of capital. En RICHARDSON, J.G. Handbook of theory and research for the sociology of education. EE.UU.: Greenwood Press, 1986, p. 241-58. Disponible en Internet: http:// www.socialcapitalgateway.org/content/paper/bourdieu-p-1986-forms-capital-richardson-j-handbook-theory-and-research-sociology-educ

BRAUDEL, F. El Mediterráneo. Madrid: Espasa Calpe, 1987.

BUTLER, R.W. Tourism Area Life Cycle. Contemporary tourism reviews. Oxford: Goodfellow, 2011.

CASTELLS, M. Entrevista con Pablo Iglesias en Otra vuelta de Tuerka. Programa \#34 - Emisión, domingo 14 de junio de 2015. Disponible en Internet: https://www.youtube.com/watch?v=dU-MD3NqmQ8

CLIFTON, N.; COOKE, P., \& HANSEN, H. K. Towards a Reconciliation of the 'Context-less' with the 'Space-less'? The Creative Class across Varieties of Capitalism: New Evidence from Sweden and the UK. Regional Studies, 2013, Vol. 47, No 2, p. 201-215. Disponible en Internet: https://doi.org/10 $.1080 / 00343404.2012 .665991$

FLORIDA, R. The Rise of the Creative Class: And How It's Transforming Work, Leisure, Community and Everyday Life. New York: Basic Books, 2004.

FLORIDA, R. La clase creativa: La transformación de la cultura del trabajo y el ocio en el siglo XXI. España: Paidós, 2010.

FLORIDA, R. The New Urban Crisis: How Our Cities Are Increasing Inequality, Deepening Segregation, and Failing the Middle Class-And What We Can Do about. Basic Books: New York, 2017.

FLORIDA, R. \& TINAGLI, I. Europe in the creative age. Europe: DEMOS, 2004. Disponible: http:// www.creativeclass.com/rfcgdb/articles/Europe_in_the_Creative_Age_2004.pdf

GONZÁLEZ REVERTÉ, F. El papel de los destinos turísticos en la transformación sociodemográfica del litoral mediterráneo español. Boletín de la Asociación Española de Geografía, 2008, Vol. 47, p. 79-107. Disponible en Internet: http://age.ieg.csic.es/boletin/47/04-GONZALEZ.pdf

GONZÁLEZ REVERTÉ, F.; ROMERO-PADILLA, Y.; MURO MORALES, I.; NAVARRO-JURADO, E. \& GÓMIS LÓPEZ, J.M. La localización de la clase creativa en ciudades turísticas. Un análisis a escala local del sistema urbano Mediterráneo español. Investigaciones Turísticas, 2016, №. 11, p. 1-29. Disponible en Internet: https://doi.org/10.14198/INTURI2016.11.01 
GORMSEN, E. The impact of tourism on coastal areas. GeoJournal, 1997, Vol. 1, No 42, p. 39-54. Disponible en Internet: http://dx.doi.org/10.1023/A:1006840622450

HALL, D. Megaciudades, ciudades mundiales y ciudades globales. En MARTíN RAMOS, A. (Ed.). Lo urbano. Barcelona: Edicions UPC, Universidad Politècnica de Catalunya, 2004, p. 117-129.

HARVEY, D. Mundos urbanos posibles. En MARTÍN RAMOS, A. (Ed.). Lo urbano. Barcelona: Edicions UPC, Universidad Politècnica de Catalunya, 2004, p. 177-198.

HARVEY, D. Ciudades rebeldes. Del derecho de la ciudad a la revolución urbana. Salamanca: Ediciones Akal, 2013.

KOOLHAAS, R. La ciudad genérica. En MARTín RAMOS, A. (Ed.). Lo urbano. Barcelona: Edicions UPC, Universidad Politècnica de Catalunya, 2004, p. 73-82.

KOOLHAAS, R. El espacio basura. Barcelona: Gustavo Gili, SL. Colección. GGmínima, 2008.

KNOWLES, T. \& CURTIS, S. (1999): The Market Viability of European Mass Tourist Destinations. A Post-Stagnation Life-cycle analysis. International Journal of Tourism Research, 1999, Vol. 1, No 4, p. 87-96. Disponible en Internet: https://onlinelibrary.wiley.com/doi/pdf/10.1002/(SICI)1522-1970(199903/04)1:2\%3C87::AID-JTR135\%3E3.0.CO;2-6

LANDRY, C. \& BIANCHINI, F. The creative city. London: Demos. 1995. Disponible en Internet: https://www.demos.co.uk/files/thecreativecity.pdf

LARSEN, J., URRY, J., \& AXHAUSEN, K. W. Networks and tourism: Mobile social life. Annals of Tourism Research, 2007, Vol. 34, No 1, p. 244-262. Disponible en Internet: https://doi.org/10.1016/j. annals.2006.08.002

LI, T. \& FLORIDA, R. Talent, technological innovation and economic growth in China. 2006. Disponible en Internet: https://www.creativeclass.com/rfcgdb/articles/Talent_Technological_Innovation_and_Economic_Growth_in_China.pdf.

MALANGA, S. The Curse of the Creative Class. Richard Florida's theories are all the rage worldwide. Trouble is, they're plain wrong. City Journal, 2004. Disponible en Internet: https://www. city-journal.org/html/curse-creative-class-12491.html

MERLOS, A. M., RODRÍGUEZ, M. \& OTERO, A. Innovaciones socio-culturales como consecuencia de las nuevas movilidades del turismo. Caso de estudio: San Carlos de Bariloche, Argentina. VI Congreso Latinoamericano de Investigación Turística, $1^{\text {a }}$ ed. EDUCO-Facultad de Turismo - Universidad Nacional del Comahue. Neuquén, 2014. Disponible en Internet: http://170.210.83.98:8080/ jspui/handle/123456789/471

MORGAN, M. Dressing Up to Survive. Tourism Management, 1991, Vol. 12, No 1, p.15-20. Disponible en Internet: https://doi.org/10.1016/0261-5177(91)90025-O 
MURPHY, E. \& REDMON, D. The role of 'hard' and 'soft' factors for accommodating creative knowledge: insights from Dublin's 'creative class'. Irish Geography, 2009, Vol. 42, No 1, p. 69-84. Disponible en Internet: https://doi.org/10.1080/00750770902815620

MURRAY, I. \& BLÁZQUEZ, M. El dinero, la aguja del tejido de la globalización capitalista. Boletín de la Asociación Española de Geografía, 2009, № 50, p. 43-80. Disponible en Internet: https://bage. age-geografia.es/ojs/index.php/bage/article/view/1113/1036

NAVARRO-JURADO, E., THIEL-ELLUL, D. \& ROMERO-PADILLA, Y. Periferias del placer: cuando turismo se convierte en desarrollismo inmobiliario-turístico. Boletín de la Asociación de Geógrafos Españoles, 2015, N067, p. 275-302. Disponible en Internet: https://bage.age-geografia.es/ojs/index. $\mathrm{php} /$ bage/article/view/1826/1742

OLANO-POZO, J. X. 'Qui viu a les destinacions turístiques i per què? Anàlisi de l'atracció de treballadors creatius i de baixa especialització a les destinacions turístiques del sistema urbà català'. Tesis doctoral dirigida por Salvador Antón y Francesc González-Reverté, Universitat Rovira i Virgili. Defendida el 12 de diciembre de 2019 en Vila-seca (Tarragona, España).

PERRY, M. Finding Space for the Creative Class: A Review of the Issues. Urban Policy and Research, 2011 Vol. 29, No 4, p. 325-341. Disponible en Internet: https://doi.org/10.1080/08111146.2011.613367

PESQUERA, M. Á., CASARES-HONTAÑÓN, P., COTO-MILLÁN, P. \& LÓPEZ DE SABANDO, V. I. Innovación empresarial, clase creativa y desarrollo económico en España. Valencia: Tirant Lo Blanch, 2010.

POON, A. Tourism, Technology and Competitive Strategies. Wallingford: CAB International. 1993.

RICHARDS, G. Creativity and tourism in the city. Current Issues in Tourism, 2014, Vol. 17, No 2, p.119144. Disponible en Internet: https://doi.org/10.1080/13683500.2013.783794

ROMERO-MARTÍNEZ, J.M., ROMERO-PADILLA, Y., \& NAVARRO-JURADO, E. Atributos urbanos contemporáneos del litoral mediterráneo en la crisis global: caso de la zona metropolitana de la Costa del Sol. Scripta Nova Revista electrónica de geografía y ciencias sociales, 2015, XIX (N0515). Disponible en Internet: http://revistes.ub.edu/index.php/ScriptaNova/article/view/15119

ROMERO-PADILLA, Y. (2016): Metamorfosis de una invención. Turismo y clase creativa: el caso de la Costa del Sol en el mediterráneo español. Tesis doctoral dirigida por Enrique Navarro Jurado, Universidad de Málaga. Defendida el 21 de enero de 2016 en Málaga (España).

ROMERO-PADILLA, Y.; NAVARRO-JURADO, E.; MALVÁREZ, G.C. The potential of international coastal mass tourism destinations to generate creative capital. Journal of Sustainable Tourism, 2016 Vol. 24, No 4, p. 574-593. Disponible en Internet: https://doi.org/10.1080/09669582.2015.1101125

RULLÁN, O. Reconversión y crecimiento de las zonas turísticas. Del fordismo al postfordismo. En TROITIÑO, M.A., GARCÍA, J.S., GARCÍA, M. (Coords.) Destinos turísticos: viejos problemas, inuevas 
soluciones? X Coloquio de Geografía del Turismo, Ocio y Recreación. Cuenca: Ediciones de la Universidad de Castilla-La Mancha, 2008, p. 587-624.

SAARINEN, J., 2006. Traditions of sustainability in tourism studies. Annals of tourism research, 2006, Vol. 33, No 4, p. 1121-1140. Disponible en Internet: https://doi.org/10.1016/j.annals.2006.06.007

SASSEN, S. Las economías urbanas y el debilitamiento de las distancias. En MARTíN RAMOS A. Lo urbano. Barcelona: Edicions UPC, Universidad Politècnica de Catalunya, 2004, p. 133-144.

SCHUSCHNY, A. \& SOTO, H. Guía metodológica. Diseño de indicadores compuestos de desarrollo sostenible. Santiago de Chile: CEPAL y GTZ, 2009. Disponible en Internet: https://www.bivica.org/ file/view/id/2485

SCOTT, A. Creative cities: conceptual issues and policy questions. Journal Of Urban Affairs, 2006, Vol. 28, No 1, p. 1-17. Disponible en Internet: https://doi.org/10.1111/j.0735-2166.2006.00256.x

SENNETT, R. El capitalismo y la ciudad. En MARTÍN RAMOS A. Lo urbano. Barcelona: Edicions UPC, Universidad Politècnica de Catalunya, 2004, p. 133-144.

STONE, I \& STUBBS, C. Enterprising expatriates: lifestyle migration and entrepreneurship in rural southern Europe. Entrepreneurship \& Regional Development, 2007, Vol. 19, No 5, pp. 433-450. Disponible en Internet: https://doi.org/10.1080/08985620701552389

STRÖM, P. \& NELSON, R. Dynamic regional competitiveness in the creative economy: can peripheral communities have a place?. The Service Industries Journal, 2010, Vol. 30, Nº4, p. 497-511. Disponible en Internet: https://doi.org/10.1080/02642060903067555

TINAGLI, I., \& FLORIDA, R. Italy in the Creative age. English summary, Milan: Creative Group Europe, 2006. Disponible en Internet: https://www.creativeclass.com/rfcgdb/articles/Italy\%20in\%20 the\%20Creative\%20Age.pdf

TURISMO Y PLANIFICACIÓN COSTA DEL SOL. Observatorio turístico de la Costa del Sol-Málaga. Málaga: Turismo y Planificación-Costa del Sol, S.L.U., 2014. Disponible en Internet: https://www. costadelsolmalaga.org/base/descargas/230214/observatorio-turistico-de-la-costa-del-sol-2014

UNCTAD. Economía Creativa. Informe 2010. EE.UU.: UNCTAD. 2010. Disponible en Internet: https:// unctad.org/es/Docs/ditctab20103_sp.pdf

URRY, J. y LASH, S. El final del turismo, en Canarias, turismo y ficción. Revista Basa. Islas Canarias: Publicación del COA Canarias, 2005, 1er Semestre.

VELA PEÓN, F. Un acto metodológico básico de la investigación social: la entrevista cualitativa. En TARRES, M.L. (coord.), Observar, escuchar y comprender. Sobre la tradición cualitativa en la investigación social. México D.F.: El Colegio de México - FLACSO México, 2001, p.63-95. 
VERA REBOLLO, J.F. \& BAÑOS CASTIÑEIRA, C.J. Renovación y reestructuración de los destinos turísticos consolidados del litoral: Las prácticas recreativas en la evolución del espacio turístico. Boletín de la Asociación Española de Geografía, 2010, № 53, pp. 329-353. Disponible en Internet: https://bage.age-geografia.es/ojs/index.php/bage/article/view/1204/1127 
